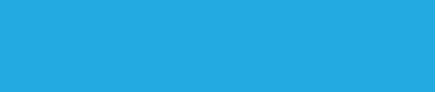

\title{
Noncanonical suppression of GH-dependent isoforms of cytochrome P450 by the somatostatin analog octreotide
}

\author{
Rajat Kumar Das*, Sarmistha Banerjee* and Bernard H Shapiro
}

Laboratories of Biochemistry, School of Veterinary Medicine, University of Pennsylvania, 3800 Spruce Street Philadelphia, Pennsylvania 19104-6009, USA

*(R K Das and S Banerjee contributed equally to this work and are each deserving of first authorship)
Correspondence should be addressed to B H Shapiro Email

shapirob@vet.upenn.edu

\begin{abstract}
Octreotide is a potent somatostatin analog therapeutically used to treat several conditions including hyper $\mathrm{GH}$ secretion in patients with acromegaly. We infused, over $30 \mathrm{~s}$, octreotide into male rats every $12 \mathrm{~h}$ for 6 days at levels considerably greater than typical human therapeutic doses. Unexpectedly, the resulting circulating GH profile was characterized by pulses of higher amplitudes, longer durations, and greater total content than normal, but still contained an otherwise male-like episodic secretory profile. In apparent disaccord, the normally elevated masculine expression levels (protein and/or mRNA) of CYP2C11 (accounting for $>50 \%$ of the total hepatic cytochrome P450 content), CYP3A2, CYP2C7, and IGF1, dependent on the episodic GH profile, were considerably downregulated. We explain this contradiction by proposing that the requisite minimal $\mathrm{GH}$-devoid interpulse durations in the masculine profile that solely regulate expression of at least CYP2C11 and IGF1 may be sufficiently reduced to suppress transcription of the hepatic genes. Alternatively, we observed that octreotide infusion may have acted directly on the hepatocytes to induce expression of immune response factors postulated to suppress CYP transcription and/or upregulate expression of several negative regulators (e.g. phosphatases and SOCS proteins) of the JAK2/STAT5B signaling pathway that normally mediates the upregulation of CYP2C11 and IGF1 by the masculine episodic GH profile.
\end{abstract}
Key Words
- cytochrome P450
- CYP2C7
- CYP2C11
- CYP3A2
- growth hormone
- IGF1
- JAK2
- octreotide
- sexual dimorphisms
somatostatin
- STAT5B

\section{Introduction}

Octreotide is a potent somatostatin analog most commonly used to reduce blood levels of GH and insulin-like growth factor-1 (IGF1), also known as somatomedin C, in acromegaly patients (Lamberts et al. 1993, Yang \& Keating 2010). Whereas a single dose of the drug to humans (Marbach et al. 1985) or rats (Turner \& Tannenbaum 1995) can profoundly reduce plasma GH concentrations for many hours, the therapeutic goal, however, is to achieve normalization of GH and IGF1 levels in patients (Lamberts et al. 1993, Yang \& Keating 2010). Although far from conclusive, it has been reported that while octreotide infusion can reduce circulating GH concentrations by $50 \%$, the pulse frequency, characteristic of men, remains undisturbed (Dimaraki et al. 2003), suggesting normal expression of $\mathrm{GH}$ profile-responsive genes. 
In addition to regulating IGF1 expression, GH regulates expression of the constituent cytochromes P450 (CYP) in rat liver as well as in every other species examined. In fact, the sex differences in CYP expression exhibited in rat, mice, and humans appear to be solely regulated by sex differences in secretory GH profiles (Shapiro et al. 1995, Dhir et al. 2006). Whereas males and females secrete similar daily amounts of GH, females secrete a so-called 'continuous' GH profile comprising numerous daily pulses interrupted by short-lived interpulses of usually low or barely detectable hormone concentrations. By contrast, the 'episodic' masculine GH profile is characterized by significantly fewer secretory bursts of the hormone separated by lengthy interpulses that are invariably devoid of GH. In fact, it is the difference between the continuous (female) and episodic (male) circulating GH profiles and not plasma hormone levels per se that are responsible for phenotypic sexual dimorphisms ranging from growth patterns to expression levels of hepatic enzymes (Jansson et al. 1985, Shapiro et al. 1995).

In the rat, CYP responses to GH regulation are nearly as variable as the number of GH-dependent isoforms. For example, expression of the major female-specific CYP2C12 is dependent on the feminine profile of continuous GH secretion exhibiting measurable hormone levels throughout the interpulses. Exposure to the masculine profile of episodic GH release characterized by GHdevoid interpulses completely prevents expression of CYP2C12 (Pampori \& Shapiro 1996, Agrawal \& Shapiro 2000). Expression of the major male-specific CYP2C11 requires the episodic 'on/off' masculine profile of secretion while the continuous feminine GH profile is completely suppressive (Pampori \& Shapiro 1996, Agrawal \& Shapiro 2000). Basically then, it is the continuous exposure to $\mathrm{GH}$, even at concentrations $95 \%$ below normal, that induces CYP2C12 expression (Pampori \& Shapiro 1996). By contrast, it is a minimum GH-devoid period separated by detectable pulses of as little as $5 \%$ of normal that signal CYP2C11 expression (Pampori \& Shapiro 1994, Agrawal \& Shapiro 2001). Another example of a CYP isoform regulated by yet a different component in the GH profile is male-specific CYP3A2. Unlike CYP2C11, CYP3A2 is maximally expressed in the GH-ablated (e.g. hypophysectomized) rat, disappears when GH is secreted continuously, but is only minimally suppressed under the influence of episodic GH (Waxman et al. 1991, Pampori \& Shapiro 1996). One more example from several other possibilities is female-predominant CYP2C7 whose maximal expression is dependent on the normal feminine continuous GH profile and is completely suppressed in the GH-ablated rat (Pampori \& Shapiro 1996). Exposure to the masculine episodic GH profile allows expression of CYP2C7 at $25-40 \%$ of normal female levels, but the profile must not stray from the physiological, i.e. no alterations in the pulse and interpulse durations, frequencies, and concentrations (Agrawal \& Shapiro 2000, 2001).

As each CYP isoform is exquisitely sensitive to the inductive effects of a different component in the secretory GH profile, we measured expression levels of key CYP isoforms as indicators or markers of possibly subtle but physiologically important abnormalities in the GH profiles resulting from octreotide infusion.

\section{Materials and methods}

\section{Animals}

Male Sprague-Dawley CD rats obtained from Charles River Laboratories (Wilmington, MA, USA) were housed in the University of Pennsylvania Laboratory Animal Resources facility under the supervision of certified Laboratory Animal Medicine veterinarians and were treated according to a research protocol approved by the University's Institutional Animal Care and Use Committee. Rats were housed under conditions of regulated temperature $\left(20-23^{\circ} \mathrm{C}\right)$ and photoperiod $(12 \mathrm{~h}$ light:12 $\mathrm{h}$ darkness cycle; lights on at $0700 \mathrm{~h}$ ).

\section{Catheter implantation and octreotide treatment}

Eight male rats at 10 weeks of age were implanted with our patented indwelling right atrial catheters as described previously (MacLeod \& Shapiro 1988, Pampori et al. 1991). After 4-5 days, serial blood samples were collected from each rat ( $40 \mu \mathrm{l}$ every $15 \mathrm{~min}$ for $8 \mathrm{~h}$ ). Another $4-5$ days later, the unrestrained and unstressed catheterized rats were infused, i.v., with $25 \mu$ g octreotide (Sandostatin) $/ \mathrm{kg}$ body weight (Bioniche Pharma, Rosemont, IL, USA) over $30 \mathrm{~s}$ and the catheter flushed with diluent. Five minutes later, serial blood samples were again collected from each rat ( $40 \mu \mathrm{l}$ every $15 \mathrm{~min}$ for $8 \mathrm{~h}$ ). Twelve hours after the first injection of octreotide, a second $25 \mu \mathrm{g} / \mathrm{kg}$ dose was given as an i.v. infusion over $30 \mathrm{~s}$ followed by flushing the catheter. During the next 5 days, rats were treated with octreotide at the same dose every $12 \mathrm{~h}$. Five minutes following the 11th dose of octreotide, serial blood samples were again collected ( $40 \mu \mathrm{l}$ every $15 \mathrm{~min}$ for $8 \mathrm{~h}$ ). Twelve hours after the previous dose, the rats received their final evening infusion of octreotide. On the following morning (10 $\mathrm{h}$ post-infusion), the rats were quickly decapitated, the

Published by Bioscientifica Ltd. 
livers quickly excised, weighed, infused with ice-cold physiological saline, and minced; a portion reserved for mRNA determinations was plunged into liquid nitrogen and subsequently stored at $-70^{\circ} \mathrm{C}$. The remaining minced liver was used for microsome preparation. In an additional experimental group, seven males (10 weeks of age) were implanted with indwelling right atrial catheters and treated with an equivalent amount of diluent ( $95 \mu \mathrm{l}$ of physiological saline/infusion) in the same manner as octreotide for 12 infusions. These rats were decapitated $10 \mathrm{~h}$ after the last treatment to serve as controls for the biochemical analyses.

\section{GH}

Plasma GH was measured using a sensitive sandwich ELISA modified from Steyn et al. (2011). A 96-well Costar high binding, type 1, polystyrene EIA/RIA Stripwell flat bottom plate (Corning, Inc., Corning, NY, USA) was coated with $50 \mu \mathrm{l}$ capture antibody (National Institute of Diabetes and Digestive and Kidney Diseases (NIDDK)-anti-rat GH (rGH)-S-5 (monkey), AFP 411S; NIDDK-National Hormone and Pituitary Program, NHPP, Torrance, CA, USA) at a final dilution of 1:40 000 and incubated overnight at $4{ }^{\circ} \mathrm{C}$. To reduce nonspecific binding, each well was subsequently incubated for $2 \mathrm{~h}$ at room temperature with $100 \mu \mathrm{l}$ blocking buffer ( $5 \%$ skim milk powder in $0.05 \%$ PBS with Tween-20 (PBS-T, 0.05\%)) followed by three careful washings for $3 \mathrm{~min}$ each time with $100 \mu \mathrm{l} 0.05 \%$ PBS-T. A standard curve was generated using a serial dilution of rGH reference preparation-2 (rGH-RP-2; AFP-3190B, NIDDK-NHPP). After $2 \mathrm{~h}$ of incubation with samples (50 $\mu \mathrm{l}$ of a 1:60 dilution; plasma: diluent), three careful washings were performed with $0.05 \%$ PBS-T for 2 min at each time. The bound samples were then incubated with $50 \mu \mathrm{l}$ detection antibody (anti-rGH A.S. (rabbit antiserum to rGH, AFP5672099Rb); NIDDK-NHPP) at a final dilution of 1:40 000 for $2 \mathrm{~h}$ followed by three careful washings for 2 min each time with $100 \mu \mathrm{l} 0.05 \%$ PBS-T. The bound complex was incubated for $90 \mathrm{~min}$ with $50 \mu \mathrm{l} \mathrm{HRP-}$ conjugated antibody (anti-rabbit, IgG; Amersham, GE Healthcare Bio-sciences Corp., Piscataway, NJ, USA) at a final dilution of 1:2000 followed by three careful washings for 3 min each time with $100 \mu 10.05 \%$ PBS-T. Addition of $100 \mu \mathrm{l} O$-phenylenediamine (Life Technologies, Grand Island, NY, USA) substrate to each well resulted in an enzymatic colorimetric reaction. This reaction was stopped after $30 \mathrm{~min}$ by addition of $50 \mu \mathrm{l} 3 \mathrm{M} \mathrm{HCl}$ and the absorbance was read at a wavelength of $490 \mathrm{~nm}$ with a M4 microplate reader (Molecular Device, Sunnyvale,
CA, USA). The concentration of rGH in each well was calculated by regression of the standard curve with hypophysectomized male rat plasma used as an appropriate blank and also subtraction of background OD at $650 \mathrm{~nm}$ from each reading for the whole assay.

\section{RNA isolation}

Total RNA from liver tissue was isolated using Trizol reagent (Life Technologies) purified with the Qiagen RNeasy mini kit and treated with DNase I in order to remove any trace of genomic DNA using RNase-Free DNase Set (Qiagen) according to the manufacturer's protocol. RNA concentrations and purity were determined by u.v. spectrophotometry (A260/280 $>1.8$ and A260/230>1.7) and integrity was verified by the intensities of $28 S$ and $18 S$ rRNA bands on a denaturing agarose gel visualized on a FluorChem IS-8800 Imager (Alpha Innotech, San Leandro, CA, USA).

\section{Northern blots}

RNA samples $(20 \mu \mathrm{g})$ were resolved on denaturing $1 \%$ agarose gels and transferred onto Nytran $\mathrm{N}$ filters from Schleicher and Schuell (Keene, NH, USA). The northern blots were probed with a $\gamma^{32} \mathrm{P}$-labeled oligonucleotide probe for Cyp2C11 and Cyp2C12 mRNA (Waxman 1991) using hybridization and high-stringency washing conditions as described previously (Pampori \& Shapiro 1996). The consistency of RNA loading between samples was confirmed by ethidium bromide staining of $18 S$ and $28 S$ ribosomal RNAs and was verified using an 185 oligonucleotide probe ( $\mathrm{Li}$ et al. 2000). The hybridized mRNA signals were quantified by scanning the autoradiographs with a FluorChem IS-8800 Imager (Alpha Innotech). The mRNA signals were normalized to the $18 S$ rRNA signals in each lane and demonstrated a mean variation of only $\pm 5 \%$, indicating that results were independent of loading errors.

\section{Quantitative RT-PCR}

Сур2C11, Сyp3A2, Сyp2C6, and Cyp2C7 gene expressions were determined by quantitative RT-PCR (qRT-PCR) using SYBR green on an Applied Biosystem 7500 Fast Real-Time PCR System (Life Technologies). RNA isolation, concentration, and purity determination were performed as mentioned earlier. cDNA synthesis was completed using the High-Capacity RNA-to-cDNA kit (Life Technologies) as per instructions with appropriate no-RT $(-\mathrm{RT})$ and

Published by Bioscientifica Ltd. 
nontemplate controls. PCR primers for Cyp2C11 (Ahluwalia et al. 2004), Сyp3A2 (Kisanga et al. 2005), Cyp2C6 (F: 5'-TCAGCAGGAAAACGGATGTG-3', R: 5'-AATCGTGGTCAGGAATAAAAATAACTC-3'), Cyp2C7 (Choi et al. 2011), and $\beta$-actin (F: $5^{\prime}$-CACGGCATTGTCACCAACTG3', R: 5'-CTGGGTCATCTTTTCACGGT-3') were synthesized by Integrated DNA Technologies (IDT, Coralville, IA, USA). To analyze Igf1 mRNA expression, an IGF1 TaqMan assay (Rn00710306_m1) was performed using $\beta$-actin (Rn00667869_m1) as the housekeeping gene on an Applied Biosystem step-one plus q-PCR instrument as per the manufacturer's recommended protocol (Life Technologies).

\section{Quantitative real-time PCR array}

Changes in the expression of genes involved in the JAK/STAT signaling pathway in normal and octreotidetreated rats were determined using real-time PCR array (Rat $\mathrm{RT}^{2}$ Profiler PCR Array; SA Biosciences, Qiagen). Isolation, concentration, and purity of total RNA from rat liver were performed as mentioned earlier. The first cDNA strand was synthesized using an $\mathrm{RT}^{2}$ First-Strand Kit (SA Biosciences). The cDNA was then applied to the $\mathrm{RT}^{2}$ Profiler PCR Array for the JAK/STAT pathway (PARN-039C) according to the manufacturer's guidelines. The qRT-PCRs were run on the Step-one plus q-PCR instrument (Life Technologies) and the data were analyzed using the online $\mathrm{RT}^{2}$ Profiler PCR Array Data Analysis (SA Biosciences) program as per instructions.

\section{Western blotting}

Hepatic microsomes were prepared from freshly isolated rat livers (Shapiro et al. 1989) and then assayed for individual CYP isoforms by western blotting (Pampori et al. 1995). STAT5B, phospho-STAT5, and phospho-STAT5B were determined using the cytosolic and/or nuclear fractions (Verma et al. 2005). Briefly, $10 \mu \mathrm{g}$ microsomal protein, $20 \mu \mathrm{g}$ cytoplasmic, or $20 \mu \mathrm{g}$ nuclear protein was electrophoresed on $0.75 \mathrm{~mm}$-thick SDS-polyacrylamide (10-12\%) gels and electroblotted onto nitrocellulose membranes. The blots were probed with monoclonal anti-rat CYP2C11, anti-rat CYP3A2 (Detroit R\&D, Inc., Franklin, MI, USA), anti-rat CYP2C12 (a gift from Dr Marika Rönnholm, Huddinge University Hospital, Huddinge, Sweden), monoclonal anti-rat CYP2B1/B2 (Oxford Biomedical Research, Oxford, MI, USA), monoclonal anti-rat CYP2C6 (Santa Cruz Biotechnology, Inc., Santa Cruz, CA, USA), anti-rabbit STAT5B (BD Biosciences,
San Jose, CA, USA) for immunoprecipitation, or antimouse STAT5B (Santa Cruz Biotechnology, Inc.), antirabbit phospho-STAT5 (Cell Signaling Technology, Inc., Danvers, MA, USA), anti-rabbit phosphotyrosine (EMD Millipore, Billerica, MA, USA) and detected with an enhanced chemiluminescence kit (Amersham, GE Healthcare Bio-sciences Corp.). Signals were normalized to a control sample repeatedly run on all blots and/or to the expression of $\beta$-actin (Sigma Chemical Co.). The protein signals were scanned and the densitometric units were obtained as integrated density values quantitated using a FluorChem IS-8800 Imager (Alpha Innotech) software supplied with the gel documentation system.

\section{Testosterone metabolism}

The metabolic products of $2 \alpha$-hydroxylase ( $2 \alpha$-hydroxy-

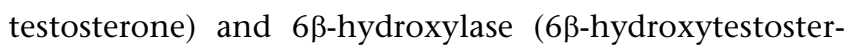
one), indicative of activity levels of CYP2C11 and CYP3A2 proteins respectively (Waxman 1991), were assayed by our previously published method (Agrawal et al. 1995a).

\section{Statistical analysis}

The ultradian patterns in plasma GH concentrations were analyzed with the aid of the Cluster analysis computer program (Veldhuis \& Johnson 1986), as we have reported previously (Agrawal et al. 1995b, Dhir \& Shapiro 2003). All data, including that obtained from the Cluster analysis program, were subjected to ANOVA and differences were determined using $t$ statistics and the Bonferroni procedure for multiple comparisons. For data obtained from PCR array, the $P$ values were calculated based on a Student's $t$-test of the replicate $2^{(-\Delta C t)}$ values for each gene in the control group and treatment groups according to online $\mathrm{RT}^{2}$ Profiler PCR Array Data Analysis (http://pcrdata analysis.sabiosciences.com/pcr/arrayanalysis.php).

\section{Results}

\section{Circulating GH profile}

Plasma GH profiles are presented as schematic representations of the actual circulating profiles (Fig. 1) as well as mathematical analyses of the characteristic components in the profile (Table 1). As controls, the rats secreted fairly 'broad' pulses every $3 \mathrm{~h}$ separated by undetectable interpulse concentrations of the hormone somewhat typical of these young adult male rats (Agrawal et al. 1995b)

Published by Bioscientifica Ltd. 

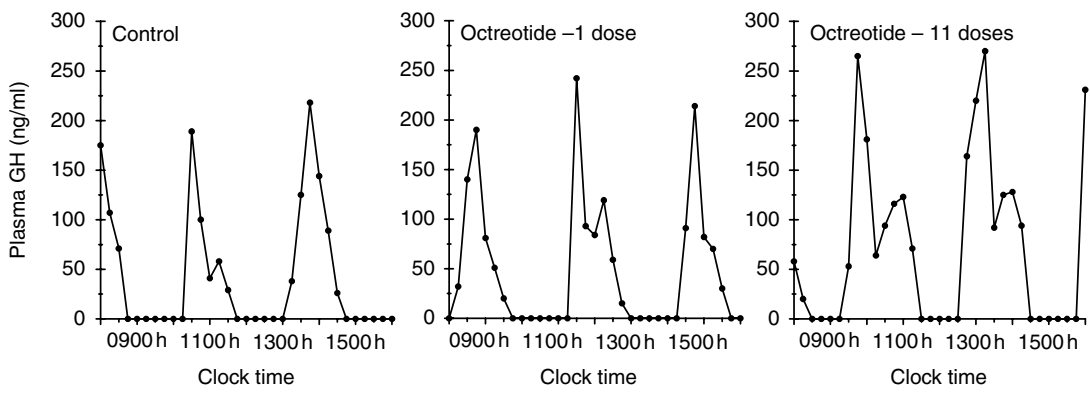

Figure 1

Plasma levels of circulating GH obtained from individual undisturbed catheterized octreotide-infused male rats. Every rat was fitted with a chronic indwelling right atrial catheter for serial blood sampling (MacLeod \& Shapiro 1988, Pampori et al. 1991). Four to five days following catheter placement, serial blood samples were collected over 8 consecutive $h$ at $15-$ min intervals (controls). Four to five days later, every rat was injected, i.v., with $25 \mu \mathrm{g}$ octreotide/kg bd wt and 5 min later, serial blood samples were again collected. Next, the rats were injected, i.v., every $12 \mathrm{~h}$ with the same dose of octreotide for a total of 11 doses. Five minutes following the last injection, serial blood collections were again obtained for $8 \mathrm{~h}$. Similar findings were obtained from six additional animals.
(In contrast to young male rats ( $\sim 70$ days old), males of 150 days of age or older typically secrete GH pulses of around $1 \mathrm{~h}$ or less duration (Agrawal et al. 1995b, Dhir \& Shapiro 2003)). Exposure to a single dose of octreotide had no measurable effects on the GH profiles. When the control rats were infused with an additional ten doses of octreotide for a total of 6 days, the basic masculine GH profile (i.e. episodic pulses interrupted by GH undetectable interpulse periods) was still apparent. However, there was a significant increase in the durations (width), amplitudes (height), and contents (area) of the GH pulses resulting in a $\sim 35 \%$ elevation in the mean concentration of the circulating hormone. Although octreotide produced no calculated statistically significant reductions in the length of the interpulse (valley) periods, one should have expected that the significant increase in the pulse durations, with no change in the interpulse intervals, would have had to result in shorter interpulses, suggesting that the lack of a statistical difference in the interpulse lengths was a spurious finding.

Table 1 Analysis of circulating GH profiles in male rats serving as their own controls and subsequently treated with one dose of octreotide followed by ten additional doses. Every rat was fitted with a chronic indwelling right atrial catheter for serial blood sampling (MacLeod \& Shapiro 1988, Pampori et al. 1991). Four to five days following catheter placement, serial blood samples were collected over 8 consecutive h at 15-min intervals. Four to five days later, every rat was injected, i.v., with $25 \mu \mathrm{g}$ octreotide/kg bd wt and $5 \mathrm{~min}$ later, serial blood samples were again collected. Next, the rats were injected, i.v., every $12 \mathrm{~h}$ with the same dose of octreotide for a total of 11 doses. Five minutes following the last injection, serial blood collections were again obtained for $8 \mathrm{~h}$. Data were analyzed with the aid of the Cluster analysis program for hormonal pulse detection (Veldhuis \& Johnson 1986) according to peak interval, period between peaks; width, duration of GH pulses, or interpulse valleys; height, amplitude of hormone peaks; area, integrated area under $\mathrm{GH}$ pulses (concentration $\times$ duration); and nadir, mean baseline $\mathrm{GH}$ concentration. Mean concentration is calculated for the entire 8-h collection period. Values are mean \pm s.D. with $n=7$

\begin{tabular}{|c|c|c|c|c|c|c|c|c|}
\hline \multirow[b]{2}{*}{ Group } & \multirow[b]{2}{*}{$\begin{array}{l}\text { Number } \\
\text { of doses }\end{array}$} & \multirow[b]{2}{*}{$\begin{array}{l}\text { Mean } \\
\text { concentration } \\
(\mathrm{ng} / \mathrm{ml})\end{array}$} & \multirow[b]{2}{*}{$\begin{array}{l}\text { Peak } \\
\text { interval (min) }\end{array}$} & \multicolumn{3}{|l|}{ Pulse } & \multicolumn{2}{|l|}{ Valley } \\
\hline & & & & $\begin{array}{l}\text { Width } \\
\text { (min) }\end{array}$ & $\begin{array}{l}\text { Height } \\
\text { (ng/ml) }\end{array}$ & $\begin{array}{l}\text { Area } \\
(\mu \mathrm{g} / \mathrm{min} \\
\text { per } \mathrm{ml})\end{array}$ & $\begin{array}{l}\text { Width } \\
\text { (min) }\end{array}$ & $\begin{array}{c}\text { Nadir } \\
\text { (ng/ml) }\end{array}$ \\
\hline Control & 0 & $49 \pm 8$ & $186 \pm 20$ & $105 \pm 15$ & $204 \pm 18$ & $9.5 \pm 1.1$ & $87 \pm 17$ & ND \\
\hline Octreotide & 1 & $48 \pm 7$ & $187 \pm 17$ & $116 \pm 20$ & $220 \pm 27$ & $11.1 \pm 1.6$ & $86 \pm 13$ & ND \\
\hline Octreotide & 11 & $65 \pm 9 *$ & $202 \pm 33$ & $134 \pm 13 *$ & $253 \pm 29 *$ & $15.6 \pm 2.2 *$ & $70 \pm 18$ & ND \\
\hline
\end{tabular}

ND, not detectable (i.e. $\geq 0.02 \mathrm{ng} / \mathrm{ml}$ ). ${ }^{\star} P<0.01$ compared with control treatment.

http://www.joe.endocrinology-journals.org DOI: 10.1530/JOE-12-0255
() 2013 Society for Endocrinology Printed in Great Britain
Published by Bioscientifica Ltd 


\section{CYP expression}

We determined the effects of octreotide on the expression levels of male-specific CYP2C11 and CYP3A2, femalespecific CYP2C12, female-predominant CYP2C6 and $\mathrm{CYP} 2 \mathrm{C} 7$, and the inducible isoforms CYP2B1 and CYP2B2 (Fig. 2). Six days of octreotide treatment resulted in a dramatic decline in CYP2C11 protein concentrations to $\sim 20 \%$ of the control values while mRNA levels as determined by qRT-PCR were reduced to $\sim 4 \%$ of normal. To confirm these unexpected results, we performed northern blotting on our samples and found, in agreement with qRT-PCR, a 90\% decrease in hepatic Cyp2C11 mRNA in males treated with octreotide and in agreement with protein levels, we observed a $65 \%$ decline in CYP2C11dependent testosterone $2 \alpha$-hydroxylase in treated rats. Expression levels of CYP3A2, another major male-specific isoform, were similarly reduced by octreotide. CYP3A2 protein, catalytic activity, and mRNA were expressed at $\sim 45$, $\sim 55$, and $\sim 30 \%$ of control levels respectively.

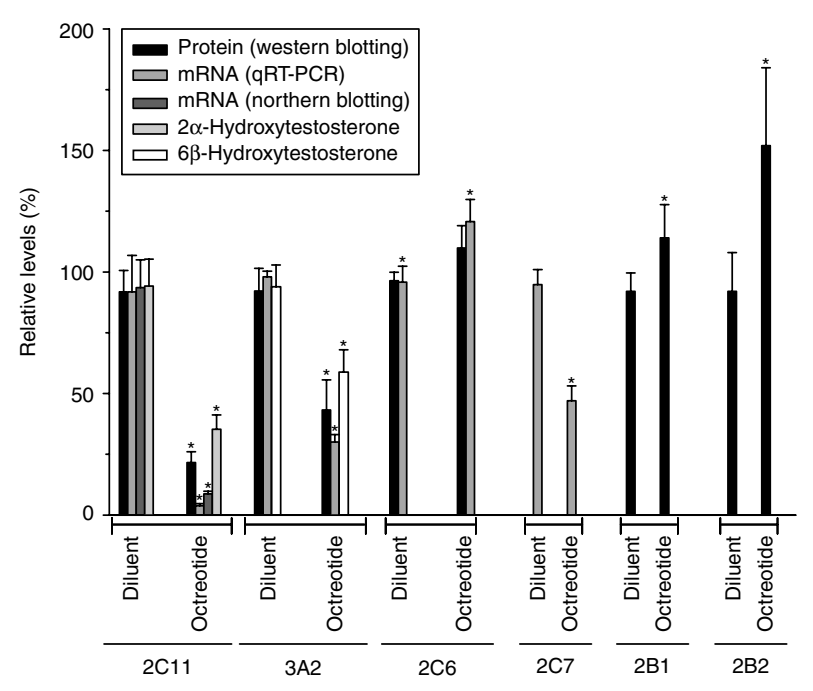

\section{Figure 2}

Relative protein concentrations, catalytic enzyme activities, and/or mRNA levels of CYP2C11, CYP3A2, CYP2C6, CYP2C7, CYP2B1, and CYP2B2 in livers from male rats treated with either diluent (controls) or octreotide. Rats fitted with our chronic indwelling atrial catheters (MacLeod \& Shapiro 1988, Pampori et al. 1991) were injected with either octreotide ( $25 \mu \mathrm{g}$ octreotide/kg bd wt) or an equivalent volume of physiological saline every $12 \mathrm{~h}$ for a total of 12 injections. Relative levels were calculated by comparing all values to the control with the highest isoform concentration (i.e. $100 \%$ ). Values are mean \pm s.D. with $n=7$. ${ }^{*} P<0.01$ compared with saline-treated controls. Comparisons are limited to the effects of octreotide on an individual isoform. Comparisons of expression levels between isoforms are not possible. In this regards, whereas CYP2C11 concentrations represent $>50 \%$ of the total CYP in normal male rat liver, CYP2B1 and CYP2B2 are inducible isoforms expressed constitutively at only nominal levels (Ryan \& Levin 1993).
CYP2C12 protein and mRNA, the principal femalespecific isoform, was undetectable in both control and octreotide-treated rats. By contrast, expression levels of CYP2C6 and CYP2C7, major female-predominant isoforms, were oppositely affected by octreotide. Hepatic CYP2C6 protein and mRNA was increased $\sim 15$ and $\sim 25 \%$ respectively in octreotide-treated rats. Cyp2C7 expression, however, was reduced $\sim 50 \%$ in the treated rats.

Both CYP2B1 and CYP2B2 are drug-inducible isoforms whose expression levels are constitutively expressed at very low concentrations (Ryan \& Levin 1993). Nevertheless, octreotide administration increased CYP2B1 protein concentrations by $\sim 25 \%$ and CYP2B 2 protein levels were increased $\sim 65 \%$; still contributing to only a small portion of the total hepatic CYP content.

\section{Igf1 expression}

One of GH's most important hepatic functions is the upregulation of $I g f 1$ transcription (Pampori \& Shapiro 1996, Davey et al. 2001). We found (not presented) that octreotide reduced $I g f 1$ mRNA levels to $68 \%$ of control values $(P<0.01)$.

\section{STAT5B expression}

Because CYP2C11 expression as well as that of IGF1 is normally dependent upon the activation of the JAK2/ STAT5B signal transduction pathway (Verma et al. 2005, Waxman \& O'Connor 2006), we measured STAT5B protein levels in hepatic cytosol of control and octreotide-treated male rats (Fig. 3). Cytosolic protein levels of the transcription factor were significantly increased in the octreotide-treated rats. As CYP2C11 and IGF1 expression require the activation (i.e. phosphorylation) and nuclear translocation of STAT5B (Waxman \& O'Connor 2006, Thangavel \& Shapiro 2007), we attempted to measure nuclear phospho-STAT5B by immunoprecipitation with STAT5B antibodies subsequently probing the precipitate with anti-phosphotyrosine as well as in the reverse order, i.e. immunoprecipitation with antiphosphotyrosine and then probing with antibodies against STAT5B (Thangavel \& Shapiro 2007). Unfortunately, neither procedure detected activated STAT5B in the nuclei of control or octreotide-treated rats (Fig. 3). Nevertheless, it was possible that the additional purification step in the immunoprecipitation procedure compromised the ability to detect small amounts of nuclear phospho-STAT5B. Accordingly, we directly measured phospho-STAT5 (though unable to differentiate phospho-STAT5B from

Published by Bioscientifica Ltd 


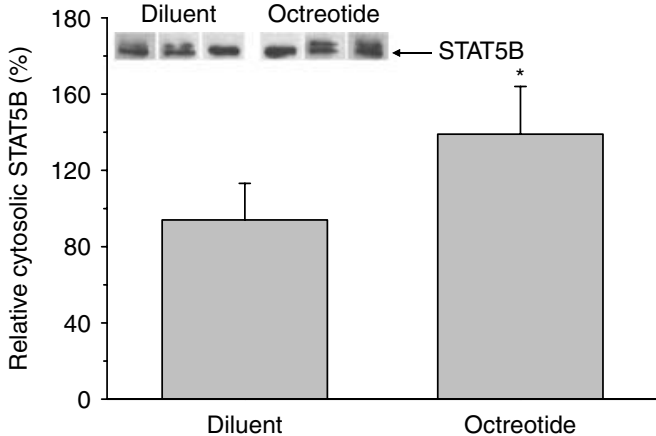

Nuclear phospho-STAT5B

$$
\text { Diluent Octreotide }
$$

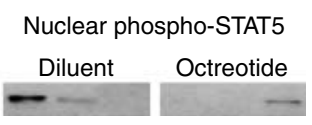

Figure 3

Analyses of cytosolic and/or nuclear STAT5B, phospho-STAT5B, and phospho-STAT5 protein levels in livers from male rats treated with either diluent (control) or octreotide. Rats fitted with our chronic indwelling atrial catheter (MacLeod \& Shapiro 1988, Pampori et al. 1991) were injected with either octreotide $(25 \mu \mathrm{g}$ octreotide $/ \mathrm{kg}$ bd wt) or an equivalent volume of physiological saline every $12 \mathrm{~h}$ for a total of 12 injections. Relative cytosolic STAT5B levels presented as mean \pm s.D. were calculated by comparing all values to the control liver with the highest isoform concentration (i.e. $100 \%$ ). ${ }^{*} P<0.01$ compared with saline-treated controls. (Note: In about half of the samples, the anti-STAT5B reaction produced a double band. According to the vendor and our use of a STAT5B standard, the lower band is STAT5B and the upper band is unknown. Moreover, the relative densitometric values would be unchanged if the upper bands were considered in the calculation as they too exhibit similar treatment differences.) Representative immunoblots are presented for all proteins. Actin levels, not presented, demonstrated equal loading. All transcription factors were measured in seven rats/group. In the case of nuclear phospho-STAT5B, immunoprecipitation (IP) used anti-phosphotyrosine (anti-pY) and immunoblotting (IB) with anti-STAT5B.

the activated $5 \mathrm{~A}$ form) in the hepatic nuclei of diluent and octreotide-treated rats (Fig. 3). Of the seven animals studied in each treatment group, the hepatic nuclei from just one control rat exhibited a strong reaction to the phospho-STAT5 antibody, another showed a weak reaction, and the remaining five rats had no reaction. Of the octreotide-infused rats, only one exhibited a nuclear reaction, albeit weak, to the antibody. These results are not surprising as phospho-STAT5B in vivo is quickly translocated to the nucleus within 15-20 min following the episodic GH pulse where it remains at detectable concentrations for about $40 \mathrm{~min}$ (Verma et al. 2005). Accordingly, it is very unlikely that our animals were killed during the brief STAT5B-responsive period.

\section{JAK/STAT-dependent genomic expression}

Having observed a dramatic downregulation in CYP2C11 expression despite a sizable upregulation of STAT5B, we investigated whether the expression of other (i.e. nonCYP) JAK/STAT-dependent genes were downregulated by octreotide. On the contrary, however, we found 14 different JAK/STAT-dependent genes upregulated by octreotide treatment, and only two genes significantly downregulated by the treatment (Table 2). Moreover, octreotide increased expression levels of Jak2, Stat3, Stat5a, and Stat5b (the latter in agreement with our STAT5B protein findings (Fig. 3)). However, none of the identified genes are members of the CYP superfamily or any of the so-called drug-metabolizing enzymes or drug transporters. Most appear to be genes involved in cell differentiation, growth, or maintenance (i.e. cellular functions), as well as immune-responsive genes. In fact, none of these groups of octreotide-responsive genes are known to be regulated by episodic GH activation of STAT5B. Rather, many of these immune response and cellular function genes are regulated by members of the JAK/STAT families other than JAK2/STAT5B (Imada \& Leonard 2000, Kisseleva et al. 2002), which, in turn, are activated by non-GH factors (e.g. prolactin, interleukin, cytokines, and lymphokines).

Table 2 Altered Jak/Stat and dependent genomic expression levels in livers of male rats treated with octreotide. Rats fitted with our chronic indwelling atrial catheters (MacLeod \& Shapiro 1988, Pampori et al. 1991) were injected with either octreotide ( $25 \mu \mathrm{g} / \mathrm{kg}$ bd wt) or an equivalent volume of physiological saline every $12 \mathrm{~h}$ for a total of 12 injections. Genomic expression levels were determined using a $\mathrm{RT}^{2}$ Profiler PCR Array for the rat Jak/Stat signaling pathway. $n=3$

\begin{tabular}{|c|c|c|c|}
\hline Function & $\begin{array}{l}\text { Gene } \\
\text { symbol }\end{array}$ & $\begin{array}{l}\text { Fold } \\
\text { change }\end{array}$ & $P$ value \\
\hline Immune response & $\begin{array}{l}\text { Jak2 } \\
\text { Stat3 } \\
\text { Stat5a } \\
\text { Stat5b } \\
\text { A2m } \\
\text { Csf1r } \\
\text { Csf2rb } \\
\text { Fcgr1a } \\
\text { II10ra } \\
\text { Irf1 }\end{array}$ & $\begin{array}{l}2.35 \uparrow \\
2.01 \uparrow \\
2.05 \uparrow \\
2.52 \uparrow \\
4.33 \uparrow \\
4.68 \uparrow \\
8.39 \uparrow \\
2.20 \uparrow \\
7.78 \uparrow \\
3.85 \uparrow\end{array}$ & $\begin{array}{l}<0.05 \\
<0.05 \\
<0.05 \\
<0.004 \\
<0.05 \\
<0.004 \\
<0.003 \\
<0.02 \\
<0.04 \\
<0.003\end{array}$ \\
\hline $\begin{array}{l}\text { Cell differentiation/ } \\
\text { growth/maintenance }\end{array}$ & $\begin{array}{l}\text { Cond1 } \\
\text { Cdkn1a } \\
\text { Egfr } \\
\text { JunB } \\
\text { Spi1 }\end{array}$ & $\begin{array}{l}2.18 \downarrow \\
8.93 \uparrow \\
2.64 \downarrow \\
3.88 \uparrow \\
5.29 \uparrow\end{array}$ & $\begin{array}{l}<0.05 \\
<0.05 \\
<0.04 \\
<0.02 \\
<0.04\end{array}$ \\
\hline $\begin{array}{c}\text { Negative regulators } \\
\text { Jak/Stat pathway }\end{array}$ & $\begin{array}{l}\text { Ptpn1 } \\
\text { Ptprc } \\
\text { Sirpa } \\
\text { Socs2 } \\
\text { Socs3 }\end{array}$ & $\begin{array}{l}2.38 \uparrow \\
3.61 \uparrow \\
2.72 \uparrow \\
2.47 \uparrow \\
3.43 \uparrow\end{array}$ & $\begin{array}{l}<0.05 \\
<0.004 \\
<0.05 \\
<0.05 \\
<0.03\end{array}$ \\
\hline
\end{tabular}

Published by Bioscientifica Ltd 
By contrast, some members of a group of octreotide upregulated genes, i.e. the negative regulators of the JAK/STAT pathway (Table 2), have been implicated in the regulation of episodic GH activation of the JAK2/ STAT5B pathway (Choi \& Waxman 2000) and may explain, in part, the actions of octreotide on CYP expression to be presented in Discussion section.

\section{Discussion}

The experimental results raise two questions. 1) Why didn't the octreotide treatment suppress circulating GH levels? 2) How then did the octreotide treatment suppress the expression of GH-dependent CYP isoforms without the expected concomitant decline in GH secretion?

It could be argued that the octreotide treatment did not suppress GH secretion because we used a less than effective dose of the analog. However, our administered dose $(25 \mu \mathrm{g}$ b.i.d./kg bd wt) was considerably greater than the most commonly effective human dose $(100 \mu \mathrm{g}$ t.i.d./patient) used to treat acromegaly (Physician's Desk Reference 2012. http://www.pdr.net/, Accessed May 28, 2012). Moreover, just a single $50 \mu \mathrm{g}$ injection of octreotide to acromegaly patients caused a rapid fall in plasma GH that took almost $9 \mathrm{~h}$ to completely recover (Marbach et al. 1985). The possibility that the rat is insensitive to the GH inhibitory effects of the somatostatin analog also seems unlikely as a dose of octreotide as small as $2 \mu \mathrm{g}$ (Pérez-Romero et al. 1999) or $15 \mu \mathrm{g} / \mathrm{kg}$ bd wt (Pless et al. 1986) has been reported to substantially $(\sim 50 \%)$ reduce GH secretion in rats.

In general, animal studies investigating the effects of octreotide on GH secretion tend to examine the inhibitory effects of just a single in vivo dose of the analog (Marbach et al. 1985, Pless et al. 1986, Turner \& Tannenbaum 1995) making it difficult to judge the relevance of these findings to our long-term study. There is, however, some evidence indicating that microgram doses of octreotide administered i.v. to adult male rats results in an enhanced rebound secretion of pulse GH when the effectiveness of the analog begins to wane and the pituitary is exposed to the next pulse release of GH-releasing hormone (GHRH; Turner \& Tannenbaum 1995). Accordingly, our observation of moderately elevated pulse amplitudes, prolonged pulse durations, and greater amounts of GH per pulse following 11 doses of octreotide may reflect an over responsiveness of the pituitary somatotrophs to the undisturbed periodic secretion of hypothalamic GHRH. Although multiple octreotide infusions did not produce the expected decline in plasma GH reported in acromegaly patients (Lamberts et al. 1993, Yang \& Keating 2010), it clearly had an effect on hepatic function.

The sexually dimorphic expression levels of hepatic CYP isoforms in the rat, and likely in all other species examined, are solely regulated by the sex differences in GH secretory patterns (Shapiro et al. 1995, Waxman \& $\mathrm{O}^{\prime}$ Connor 2006). CYP2C11 is the predominant isoform in the male rat accounting for $>50 \%$ of the total content of hepatic CYPs (Ryan \& Levin 1993). Masculine expression levels of both male-specific CYP2C11 and CYP3A2 are solely dependent on exposure to the episodic GH secretory profile characteristic of the male, whereas the feminine continuous GH profile completely suppresses expression of the isoforms. Although femalepredominant $\mathrm{CYP} 2 \mathrm{C} 7$ is expressed at much lower concentrations in male liver, these masculine levels are still dependent on the normal episodic GH profile of the male rat as disruption in the masculine GH profile will suppress CYP2C7 expression. Whereas the sexually dimorphic concentrations of female-predominant hepatic CYP2C6 are determined by the sex differences in the GH secretory profiles, considerable levels of the isoform are expressed in the absence of GH indicating a high degree of $\mathrm{GH}$ independence (Pampori \& Shapiro 1996, Agrawal \& Shapiro 2000, 2001). CYP2B1 and CYP2B2 are druginducible (e.g. phenobarbital) isoforms, nominally, at best, expressed constitutively, and moderately responsive to the sexually dimorphic GH secretory profiles (Agrawal \& Shapiro 1995). Lastly, although not a CYP, GH regulation of IGF1 expression has been extensively reported (Martinelli et al. 2008).

How then did octreotide alter the expression of these GH-dependent proteins without any notable disruptions in the masculine GH secretory profile? To answer this seeming contradiction, we focused our attention on CYP2C11, a paradigm for studies examining the molecular mechanism(s) activated by episodic GH secretion (Waxman \& O'Connor 2006, Thangavel \& Shapiro 2007). While it is correct that the masculine levels of the sex-dependent CYP isoforms are dependent on exposure to the episodic GH profile, the profile is composed of various 'signaling elements' to which each isoform is independently responsive. These signals may be recognized by the hepatocyte in the frequencies, concentrations, and/or durations of the pulse and interpulse periods. Alternatively, the hepatocyte can monitor the mean plasma concentration of the hormone (Pampori \& Shapiro 1996, Agrawal \& Shapiro 2000). The signal in the masculine GH profile regulating CYP2C11, and likely CYP3A2, is a minimum GH-devoid interpulse period.

Published by Bioscientifica Ltd. 
The normal pulse amplitudes can be reduced by $90-95 \%$ or elevated fourfold, and the pulse frequencies can be reduced to just four a day, and still CYP2C11 expression will be normal (Waxman et al. 1991, Agrawal \& Shapiro $2000,2001)$. However, as the duration of the physiological GH-devoid interpulse becomes shorter, the hepatic CYP2C11 discriminator recognizes the profile as feminine (i.e. constant), suppressing expression of the isoforms (Agrawal \& Shapiro 2001). In this regard, octreotide appeared to have reduced the duration of the $\mathrm{GH}$ interpulse, which may have been a critical element in the resulting suppression of CYP2C11 as well as CYP3A2. In support of our conclusion, there are some reports indicating that the somatostatin analog can decrease drug metabolism in patients (Physician's Desk Reference 2012. http://www.pdr.net/, Accessed May 28, 2012), and data from octreotide-infused young men suggest shortened interpulses in the monitored GH profile (Dimaraki et al. 2003).

It has also been reported that a toxin-induced acute inflammatory response can reduce hepatic Cyp2C11 mRNA to $5-25 \%$ of normal in $24 \mathrm{~h}$ (Wright \& Morgan 1990). This rapid response likely precludes any involvement of GH. However, the response may involve the synthesis of 'positive acute-phase proteins' like $\alpha_{2}$-macroglobulin (A2m) (Kushner 1982). Twice-daily observations of our animals indicated no acute or even moderate inflammation. In fact, normal body weight gain of $\sim 5 \mathrm{~g}$ /day during octreotide infusion indicates healthy animals. However, we did observe a greater than fourfold increase in hepatic expression levels of $A 2 \mathrm{~m}$ in the octreotide-treated rats. As A2m is a GH-binding protein (Kratzsch et al. 1995) and an upregulation in A2m has been correlated with a downregulation of several CYPs (Beigel et al. 2008), the octreotide-induced expression of A2m may have contributed to the general CYP suppression in our experimental animals.

A final explanation for our results may involve GHindependent mechanisms. Somatostatins have numerous extra-pituitary effects including the activation of the immune response, inhibition of cellular proliferation, and more specifically blocking the secretion of serotonin, gastrin, vasoactive intestinal peptide, secretin, motilin, pancreatin polypeptide, glucagons, and insulin explaining their therapeutic use in treating carcinoid tumors and vasoactive intestinal peptide tumors (Marbach et al. 1985, Lamberts et al. 1993, Yang \& Keating 2010). We have seen the multiple extra-pituitary effects of octreotide by the number of genes involved in the immune response, cell differentiation, growth, and maintenance affected by the analog (Table 2). Although studies examining the extrapituitary actions of octreotide are limited, there are reports demonstrating octreotide inhibition of cyclin D1 (Ccnd1; Ferrante et al. 2006) and epidermal growth factor receptor (Egfr) expression (Lai et al. 2003, Shen et al. 2011) as we too report.

It seems improbable that expression of the 20 hepatic genes we found to be regulated by octreotide is involved in CYP expression. Rather, it more likely indicates that somatostatin and its analog normally regulate a myriad of functions as broadly classified earlier. However, a few of the genes upregulated by octreotide are known to be involved in CYP2C11 and IGF1 expression. GH signaling in liver by the episodic profile (in contrast to the continuous profile) is initiated by hormone binding and the resulting activation of GH receptors on the surface of the target cells. This allows for the recruitment and/or activation of two molecules of JAK2, which then crossphosphorylate each other as well as phosphorylating the receptor on key tyrosine residues. STAT5B, a latent transcription factor, binds to these phosphorylated receptor docking sites, is in turn phosphorylated, homodimerizes, and translocates to the nucleus where it binds to promoter sites initiating transcription of CYP2C11 (Choi \& Waxman 2000, Thangavel \& Shapiro 2007) and IGF1 (Davey et al. 2001). We found that octreotide induced a greater than twofold increase in Jak2 mRNA and Stat $5 b$ mRNA, with the latter being increased at the protein level as well. These findings would seem to be in direct contradiction with the accompanying $\sim 90 \%$ decline in CYP2C11 mRNA and protein. However, the episodic GH/JAK2/STAT5B signal transduction pathway is negatively regulated by tyrosine phosphatases (Frank 2001, Waxman \& O'Connor 2006) and suppressors of cytokine signaling, i.e. SOCS/CIS (Choi \& Waxman 2000, Thangavel \& Shapiro 2007).

In agreement with earlier studies reporting octreotideinduced activation of tyrosine phosphatases (Held-Feindt et al. 2001, Murray et al. 2004) and then subsequent inhibition of STAT5B activation and nuclear translocation (Murray et al. 2004), we observed an octreotide upregulation of several tyrosine phosphatases as well as Socs genes. Accordingly, we propose that the somatostatin analog induces the overexpression of hepatic negative regulators of the JAK2/STAT5B pathway preventing episodic GH induction of CYP2C11 expression. The upregulation of Jak2 and $S t a t 5 b$ may reflect a reflex overexpression in response to inhibition of the JAK2/STAT5B signaling pathway.

In summary, we have found that circulating $\mathrm{GH}$ profiles in male rats infused with octreotide every

Published by Bioscientifica Ltd. 
$12 \mathrm{~h}$ for 6 days were characterized by larger than normal pulses in otherwise male-like episodic secretory profiles. In apparent disaccord, several episodic GH-dependent CYP isoforms as well as $I g f 1$ were concurrently downregulated by the analog. We explain this contradiction by identifying octreotide-induced subtle abnormalities in 'signals' in the masculine GH profile normally required for male-like expression levels of CYPs and IGF1, induction of immune response factors postulated to suppress CYP expression, and/or by octreotide-induced overexpression of negative regulators of the JAK2/STAT5B pathway normally mediating episodic GH inductions of a least CYP2C11 and IGF1.

\section{Declaration of interest}

The authors declare that there is no conflict of interest that could be perceived as prejudicing the impartiality of the research reported.

\section{Funding}

This work was supported by National Institute of Health Eunice Kennedy Shrive National Institute of Health and Human Development (Grant HD-061285).

\section{References}

Agrawal AK \& Shapiro BH 1995 Phenobarbital induction of hepatic CYP2B1 and CYP2B2: pretranscriptional and post-transcriptional effects of gender, adult age, and phenobarbital dose. Molecular Pharmacology 49 523-531.

Agrawal AK \& Shapiro BH 2000 Differential expression of genderdependent hepatic isoforms of cytochrome P-450 by pulse signals in the circulating masculine episodic growth hormone profile of the rat. Journal of Pharmacology and Experimental Therapeutics 292 228-237.

Agrawal AK \& Shapiro BH 2001 Intrinsic signals in the sexually dimorphic circulating growth hormone profiles of the rat. Molecular and Cellular Endocrinology 173 167-181. (doi:10.1016/S0303-7207(00)00401-9)

Agrawal AK, Pampori NA \& Shapiro BH 1995a Thin-layer chromatographic separation of regioselective and stereospecific androgen metabolites. Analytical Biochemistry 224 455-457. (doi:10.1006/abio.1995.1071)

Agrawal AK, Pampori NA \& Shapiro BH 1995b Neonatal phenobarbitalinduced defects in age- and sex-specific growth hormone profiles regulating monooxygenases. American Journal of Physiology. Endocrinology and Metabolism 268 E439-E445.

Ahluwalia A, Clodfelter KH \& Waxman DJ 2004 Sexual dimorphism of rat liver gene expression: regulatory role of growth hormone revealed by deoxyribonucleic acid microarray analysis. Molecular Endocrinology 18 747-760. (doi:10.1210/me.2003-0138)

Beigel J, Fella K, Kramer PJ, Kroeger M \& Hewitt P 2008 Genomics and proteomics analysis of cultured primary rat hepatocytes. Toxicology In Vitro 22 171-181. (doi:10.1016/j.tiv.2007.06.019)

Choi HK \& Waxman DJ 2000 Pulsatility of growth hormone (GH) signalling in liver cells: role of the JAK-STAT5b pathway in GH action. Growth Hormone \& IGF Research 10(Suppl b) 1-8. (doi:10.1016/S10966374(00)80002-7)

Choi S-Y, Fischer L, Yang K, Chung H \& Jeong H 2011 Isoform-specific regulation of cytochrome $\mathrm{P} 450$ expression and activity by estradiol in female rats. Biochemical Pharmacology 81 777-782. (doi:10.1016/j.bcp. 2010.12.019)

Davey HW, Xie T, McLachlan MJ, Wilkins RJ, Waxman DJ \& Grattan DR 2001 STAT5b is required for GH-induced liver Igf-1 gene expression. Endocrinology 142 3836-3841. (doi:10.1210/en.142.9.3836)

Dhir RN \& Shapiro BH 2003 Interpulse growth hormone secretion in the episodic plasma profile causes the sex reversal of cytochrome P450s in senescent male rats. PNAS 100 15224-15228. (doi:10.1073/pnas. 2434273100)

Dhir RN, Dworakowski W, Thangavel C \& Shapiro BH 2006 Sexually dimorphic regulation of hepatic isoforms of human cytochrome P450 by growth hormone. Journal of Pharmacology and Experimental Therapeutics 316 87-94. (doi:10.1124/jpet.105.093773)

Dimaraki EV, Jaffe CA, Bowers CY, Marbach P \& Barkan AL 2003 Pulsatile and nocturnal growth hormone secretions in men do not require periodic declines of somatostatin. American Journal of Physiology. Endocrinology and Metabolism 285 E163-E170.

Ferrante E, Pellegrini C, Bondioni S, Peverelli E, Locatelli M, Gelmini P, Luciani P, Peri A, Mantovani G, Bosari S et al. 2006 Octreotide promotes apoptosis in human somatotroph tumor cells by activating somatostatin receptor type 2. Endocrine-Related Cancer 13 955-962. (doi:10.1677/erc.1.01191)

Frank SJ 2001 Growth hormone signaling and its regulation: preventing too much of a good thing. Growth Hormone \& IGF Research 11 201-212. (doi:10.1054/ghir.2001.0237)

Held-Feindt J, Forstreuter F, Pufe T \& Mentlein R 2001 Influence of the somatostatin receptor sst 2 on growth factor signal cascades in human glioma cells. Molecular Brain Research 87 12-21. (doi:10.1016/S0169$328 \mathrm{X}(00) 00225-4)$

Imada K \& Leonard WJ 2000 The Jak-STAT pathway. Molecular Immunology 37 1-11. (doi:10.1016/S0161-5890(00)00018-3)

Jansson JO, Edén S \& Isaksson O 1985 Sexual dimorphism in the control of growth hormone secretion. Endocrine Reviews 6 128-150. (doi:10.1210/ edrv-6-2-128)

Kisanga ER, Moi LLH, Gjerde J, Mellgren G \& Lien EA 2005 Induction of hepatic drug-metabolising enzymes and tamoxifen metabolite profile in relation to administration route during low-dose treatment in nude rats. Journal of Steroid Biochemistry and Molecular Biology 94 489-498. (doi:10.1016/j.jsbmb.2004.12.037)

Kisseleva T, Bhattacharya S, Braunstein J \& Schindler CW 2002 Signaling through the JAK/STAT pathway, recent advances and future challenges. Gene 285 1-24. (doi:10.1016/S0378-1119(02) 00398-0)

Kratzsch J, Selisko T \& Birkenmeier G 1995 Identification of transformed $\alpha_{2}$-macroglobulin as a growth hormone-binding protein in human blood. Journal of Clinical Endocrinology and Metabolism 80 585-590. (doi:10.1210/jc.80.2.585)

Kushner I 1982 The phenomenon of the acute phase response. Annals of the New York Academy of Sciences 389 39-48. (doi:10.1111/j.1749-6632. 1982.tb22124.x)

Lai HS, Chen Y, Chang KJ \& Chen WJ 2003 Effects of octreotide on epidermal growth factor receptor, tissue plasminogen activator, and plasminogen activator inhibitor during intraperitoneal adhesion formation. Journal of Gastroenterology 38 555-560.

Lamberts SWJ, Hofland LJ, de Herder WW, Kwekkeboom DJ, Reubi JC \& Krenning EP 1993 Octreotide and related somatostatin analogs in the diagnosis and treatment of pituitary disease and somatostatin receptor scintigraphy. Frontiers in Neuroendocrinology 14 27-55. (doi:10.1006/ frne.1993.1002)

Li YQ, Prentice DA, Howard ML, Mashford ML, Wilson JS \& Desmond PV 2000 Alcohol up-regulates UDP-glucuronosyltransferase mRNA expression in rat liver and in primary rat hepatocyte culture. Life Sciences 66 575-584. (doi:10.1016/S0024-3205(99)00630-X)

MacLeod JN \& Shapiro BH 1988 Repetitive blood sampling in unrestrained and unstressed mice using a chronic indwelling 
right atrial catheterization apparatus. Laboratory Animal Science $\mathbf{3 8}$ 603-608.

Marbach P, Neufeld M \& Pless J 1985 Clinical applications of somatostatin analogs. Advances in Experimental Medicine and Biology 188 339-353.

Martinelli CE Jr, Custódio RJ \& Aguiar-Oliveira MH 2008 Physiology of the GH-IGF axis. Arquivos Brasileiros de Endocrinologia e Metabologia 52 717-725. (doi:10.1590/S0004-27302008000500002)

Murray RD, Kim K, Ren S-G, Chelly M, Umehara Y \& Melmed S 2004 Central and peripheral actions of somatostatin on the growth hormone-IGF-I axis. Journal of Clinical Investigation 114 349-356.

Pampori NA \& Shapiro BH 1994 Over-expression of CYP2C11, the major male-specific form of hepatic cytochrome P450, in the presence of nominal pulses of circulating growth hormone in adult male rats neonatally exposed to low levels of monosodium glutamate. Journal of Pharmacology and Experimental Therapeutics 271 1067-1073.

Pampori NA \& Shapiro BH 1996 Feminization of hepatic cytochrome P450s by nominal levels of growth hormone in the feminine plasma profile. Molecular Pharmacology 50 1148-1156.

Pampori NA, Agrawal AK \& Shapiro BH 1991 Renaturalizing the sexually dimorphic profiles of circulating growth hormone in hypophysectomized rats. Acta Endocrinologica 124 283-289.

Pampori NA, Pampori MK \& Shapiro BH 1995 Dilution of the chemiluminescence reagents reduces the background noise on western blots. Biotechniques 18 588-590.

Pérez-Romero A, Rol de Lama MAR, Ariznavarreta C \& Tresguerres JAF 1999 Effect of long-term GHRH and somatostatin administration on GH release and body weight in prepubertal female rats. Journal of Physiology and Biochemistry 55 315-324.

Pless J, Bauer W, Briner U, Doepfner W, Marbach P, Maurer R, Petcher TJ, Reubi J-C \& Vonderscher J 1986 Chemistry and pharmacology of SMS 201-995, a long-acting octapeptide analogue of somatostatin. Scandinavian Journal of Gastroenterology 21(Suppl 119) 54-64. (doi:10.3109/00365528609087432)

Ryan DE \& Levin W 1993 Age- and gender- related expression of rat liver cytochrome P450. In Cytochrome P450 (Handbook of Experimental Pharmacology), pp 461-476. Eds JB Schenkman \& H Greim. Berlin: Springer-Veslag.

Shapiro BH, MacLeod JN, Pampori NA, Morrissey JJ, Lapenson DP \& Waxman DJ 1989 Signalling elements in the ultradian rhythm of circulating growth hormone regulating expression of sex-dependent forms of hepatic cytochrome P450. Endocrinology 125 2935-2944. (doi:10.1210/endo-125-6-2935)
Shapiro BH, Agrawal AK \& Pampori NA 1995 Gender differences in drug metabolism regulated by growth hormone. International Journal of Biochemistry \& Cell Biology 27 9-20. (doi:10.1016/13572725(94)00056-5)

Shen Y, Ren ML, Shi YH, Zhang YX \& Cai YL 2011 Octreotide enhances the sensitivity of the SKOV3/DDP ovarian cancer cell line to cisplatin chemotherapy in vitro. Experimental and Therapeutic Medicine 2 1171-1176.

Steyn FJ, Huang L, Ngo ST, Leong JW, Tan HY, Xie TY, Parlow AF, Veldhuis JD, Waters MJ \& Chen C 2011 Development of a method for the determination of pulsatile growth hormone secretion in mice. Endocrinology 152 3165-3171. (doi:10.1210/en.2011-0253)

Thangavel C \& Shapiro BH 2007 A molecular basis for the sexually dimorphic response to growth hormone. Endocrinology 148 2894-2903. (doi:10.1210/en.2006-1333)

Turner JP \& Tannenbaum GS 1995 In vivo evidence of a positive role for somatostatin to optimize pulsatile growth hormone secretion. American Journal of Physiology. Endocrinology and Metabolism 269 E683-E690.

Veldhuis JD \& Johnson ML 1986 Cluster analysis: a simple, versatile, and robust algorithm for endocrine pulse detection. American Journal of Physiology 250 E486-E493.

Verma AS, Dhir RN \& Shapiro BH 2005 Inadequacy of the Janus kinase $2 /$ signal transducer and activator of transcription signal transduction pathway to mediate episodic growth hormone-dependent regulation of hepatic CYP2C11. Molecular Pharmacology 67 891-901. (doi:10.1124/ mol.104.005454)

Waxman DJ 1991 Rat hepatic P450IIA and P450IIC subfamily expression using catalytic, immunochemical, and molecular probes. Methods in Enzymology 206 249-267. (doi:10.1016/0076-6879(91)06095-K)

Waxman DJ \& O'Connor C 2006 Growth hormone regulation of sex-dependent liver gene expression. Molecular Endocrinology 20 2613-2629. (doi:10.1210/me.2006-0007)

Waxman DJ, Pampori NA, Ram PA, Agrawal AK \& Shapiro BH 1991 Interpulse interval in circulating growth hormone patterns regulates sexually dimorphic expression of hepatic cytochrome P450. PNAS $\mathbf{8 8}$ 6868-6872. (doi:10.1073/pnas.88.15.6868)

Wright K \& Morgan ET 1990 Transcriptional and post-transcriptional suppression of P450IIC11 and P450IIC12 by inflammation. FEBS Letters 271 59-61. (doi:10.1016/0014-5793(90)80371-O)

Yang LPH \& Keating GM 2010 Octreotide long-acting release (LAR): a review of its use in the management of acromegaly. Drugs 70 1745-1769. (doi:10.2165/11204510-000000000-00000)

Received in final form 24 September 2012

Accepted 17 October 2012

Accepted Preprint published online 17 October 2012
(C) 2013 Society for Endocrinology Printed in Great Britain
Published by Bioscientifica Ltd. 